\title{
Specific dynamic variations in the peripheral blood lymphocyte subsets in COVID-19 and severe influenza A patients: a retrospective observational study
}

Fang Qian ${ }^{1 \dagger}$, Guiju Gao ${ }^{1 \dagger}$, Yangzi Song ${ }^{1+}$, Yanli Xu ${ }^{1+}$, Aibin Wang ${ }^{1}$, Sa Wang ${ }^{1}$, Yiwei Hao ${ }^{2}$, Meiling Chen ${ }^{2}$, Xiaoyang $\mathrm{Ma}^{3}$, Tianwei Zhao ${ }^{1}$, Xiaodi Guo ${ }^{4}$, Zhihai Chen ${ }^{1 *}$ and Fujie Zhang ${ }^{1 *}$ (i)

\begin{abstract}
Background: Both COVID-19 and influenza A contribute to increased mortality among the elderly and those with existing comorbidities. Changes in the underlying immune mechanisms determine patient prognosis. This study aimed to analyze the role of lymphocyte subsets in the immunopathogenesisof COVID-19 and severe influenza A, and examined the clinical significance of their alterations in the prognosis and recovery duration.

Methods: By retrospectively reviewing of patients in four groups (healthy controls, severe influenza A, non-severe COVID-19 and severe COVID-19) who were admitted to Ditan hospital between 2018 to 2020, we performed flow cytometric analysis and compared the absolute counts of leukocytes, lymphocytes, and lymphocyte subsets of the patients at different time points (weeks 1-4).

Results: We reviewed the patients' data of 94 healthy blood donors, 80 Non-severe-COVID-19, 19 Severe-COVID-19 and 37 severe influenza $A$. We found total lymphocytes $\left(0.81 \times 10^{9} / \mathrm{L}\right.$ vs $1.74 \times 10^{9} / \mathrm{L}, P=0.001 ; 0.87 \times 10^{9} / \mathrm{L}$ vs $1.74 \times 10^{9} / \mathrm{L}, P<0.0001$, respectively) and lymphocyte subsets ( $T$ cells, CD4 $4^{+}$and $C D 8^{+} T$ cell subsets) of severe COVID-19 and severe influenza A patients to be significantly lower than those of healthy donors at early infection stages. Further, significant dynamic variations were observed at different time points (weeks 1-4).
\end{abstract}

Conclusions: Our study suggests the plausible role of lymphocyte subsets in disease progression, which in turn affects prognosis and recovery duration in patients with severe COVID-19 and influenza A.

Keywords: Coronavirus disease-19 (COVID-19), Severe influenza A, Lymphocyte, T cells subsets

\footnotetext{
*Correspondence: chenzhihai0001@126.com; treatment@chinaaids.cn

${ }^{\dagger}$ Fang Qian, Guiju Gao, Yangzi Song and Yanli Xu contributed equally to this work.

'Clinical and Research Center of Infectious Diseases, Beijing Ditan Hospital,

Capital Medical University, No.8, Jing shun Dong jie, Chaoyang 100015,

District Beijing, China

Full list of author information is available at the end of the article
}

(C) The Author(s). 2020 Open Access This article is licensed under a Creative Commons Attribution 4.0 International License, which permits use, sharing, adaptation, distribution and reproduction in any medium or format, as long as you give appropriate credit to the original author(s) and the source, provide a link to the Creative Commons licence, and indicate if changes were made. The images or other third party material in this article are included in the article's Creative Commons licence, unless indicated otherwise in a credit line to the material. If material is not included in the article's Creative Commons licence and your intended use is not permitted by statutory regulation or exceeds the permitted use, you will need to obtain permission directly from the copyright holder. To view a copy of this licence, visit http://creativecommons.org/licenses/by/4.0/ The Creative Commons Public Domain Dedication waiver (http://creativecommons.org/publicdomain/zero/1.0/) applies to the data made available in this article, unless otherwise stated in a credit line to the data. 


\section{Background}

Since the time the World Health Organization (WHO) declared the infection caused by the severe acute respiratory syndrome coronavirus 2 (SARS-CoV-2), Coronavirus Disease 2019 (COVID-19), a global pandemic, has seriously threatened to global public health and is still expanding. The clinical manifestations of COVID-19 can be mild or severe, which the incidence of mortality is higher among the elderly and among those with preexisting comorbidities, including hypertension, cardiovascular and cerebrovascular disease, and diabetes, similar to influenza [1]. In addition, their modes of transmission are by contact, droplets, or fomites $[2,3]$. While relatively little is known about the immunopathological aspects of SARS-CoV-2 virus, there exists vast literature on the possible underlying mechanisms of disease pathogenesis of Influenza A virus.

As previous studies demonstrated that infection of humans with influenza A virus leads to an induction of apoptosis of a portion of $\mathrm{CD}_{3}^{+}, \mathrm{CD}_{4}^{+}, \mathrm{CD}^{+}$, and $\mathrm{CD} 19^{+}$ lymphocytes, thus resulting in a severe transient leukopenia, and that lymphocyte apoptosis, which represents a part of an overall beneficial immune response could be a possible mechanism of disease pathogenesis $[4,5]$.

Although the precise immunopathogenesis of COVID19 is unknown, genome studies and standard blood investigations suggest involvement of the immune system. Previous studies have shown that severe leukopenia and lymphopenia occur during early stages of infection and subsequently become less prominent as the disease progresses in patients with severe COVID-19 [6, 7]. Furthermore, as lymphopenia developed in severe COVID19 cases, it was shown to be a predictor of prognosis and a reliable indicator of disease severity and hospitalization in COVID-19 patients [8]. However, data on kinetic alterations in lymphocytes after COVID-19 infection are sparse. To the best of our knowledge, there are no comparative studies focusing on the dynamic variations in lymphocyte subsets of patients with influenza A and SARS-Cov-2 infections. Whether changes in the underlying immune mechanisms determine patient prognosis and recovery in COVID-19 remains unclear. Therefore, in view of the above, in this retrospective study, we analyzed the role of lymphocytes and lymphocyte subsets in the immunopathogenesis of COVID-19 and severe influenza $\mathrm{A}$, to provide us with valuable insights for better understanding of the underlying immune mechanisms following SARS-Cov-2 and severe influenza A infections.

\section{Methods}

\section{Study design and participants}

We retrospectively reviewed the clinical data of all patients who were confirmed to have COVID-19 and were admitted to the Beijing Ditan Hospital from January 20, 2020 to March 17, 2020. In addition, all patients with severe influenza $\mathrm{A}$ who were admitted to Ditan hospital between 2018 to 2020 were recruited for this study. A group of healthy blood donors who were previously recruited in 2018 were used to provide data for the healthy controls in this study. This study was approved by the Ethics Committee of Beijing Ditan Hospital (No. 202000601). The need for individual consent was waived because of the retrospective nature of the study.

The patients with COVID-19 were divided into nonsevere and severe pneumonia groups according to the Diagnosis and Treatment Protocols for Patients with COVID-19 (Trial Version 7, Revised) [9]. The diagnostic criteria for patients with non-severe COVID-19 included: (1) Epidemiological history, (2) Fever or other respiratory symptoms, (3) Typical computed tomography $(\mathrm{CT})$ image abnormities of viral pneumonia, and (4) Positive result of reverse transcription-polymerase chain reaction (RT-PCR) for SARS-CoV-2 Ribonucleic acid (RNA), while those with severe COVID-19 additionally met at least one of the following conditions: (1) Shortness of breath or dyspnea, with a respiratory rate of 30 times/min, (2) Oxygen saturation (resting state) 93\%, or (3) $\mathrm{PaO} 2$ / FiO2 $300 \mathrm{mmHg}$.

Samples of patients with COVID-19 that were SARS$\mathrm{CoV}-2$ positive based on nucleic acid detection and showed the presence of lymphocyte subset population for approximately 4 weeks after onset, where lymphocyte subset analyses were performed at least twice within the 4 weeks duration, were included in this study. However, those samples that were SARS-CoV-2 nucleic acid positive and either lacked or showed the presence of only one lymphocyte subset population for approximately 4 weeks after onset were not considered for this study.

Patients with severe influenza were diagnosed based on Influenza: Diagnosis and Treatment (2019) [10]. The diagnostic criteria were as follows: sustained high fever> 3 days accompanied by severe cough, coughing up sputum or bloody sputum, or chest pain; rapid breathing rate, respiratory distress, and cyanosis of lips; change in consciousness such as unresponsiveness, drowsiness, restlessness, or convulsions; Severe vomiting, diarrhea, dehydration; presence of symptoms associated with pneumonia; exacerbation of pre-existing conditions and/ or diseases; other clinical conditions requiring hospitalization. Patients with severe influenza A admitted to our hospital who met the above criteria were included in this study. Patients were excluded if an alternative diagnosis, such as the presence of influenza $B$, parainfluenza, respiratory syncytial virus, adenovirus, mycoplasma, chlamydia, legionella was determined.

Healthy controls who tested negative for human immunodeficiency virus (HIV) infection, hepatitis viral 
infections, systemic infections, connective tissue diseases, cancer, or any other abnormal tumor markers were considered.

Patients in four groups (non-severe COVID-19 and severe COVID-19, severe influenza $A$, and healthy controls) excluded minors younger than 18 years old and pregnant women.

\section{Data collection}

The information related to age, gender, onset of symptoms, medical history of pre-existing comorbidities (hypertension, diabetes, chronic obstructive pulmonary disease (COPD), cardiovascular disease, chronic kidney disease, and/or autoimmune disease), severity assessment on admission, laboratory findings, and treatment regimen for each patient was extracted from electronic medical records.

\section{Laboratory confirmation}

Laboratory confirmation tests for COVID-19 were performed by Beijing Center for Disease Control and Prevention (CDC) and Beijing Ditan Hospital. Throat swab and/or sputum specimens were collected from all patients at admission and were tested the same day. Patients were confirmed to be positive for SARS-CoV-2 nucleic acid by real-time fluorescent reverse transcriptase-polymerase chain reaction assay, according to the WHO interim guidance for COVID-19 [11].

The diagnosis of severe influenza virus infection was confirmed by RT-PCR of nasopharyngeal swabs [10].

\section{Flow cytometric analyses}

To explore the cellular immune response of patients with severe and non-severe COVID-19 and severe influenza A, peripheral blood samples ( $2 \mathrm{~mL}$ each) were collected from healthy controls and all patients at week 1 (0-7 days), week 2 (8-14 days), week 3 (15-21 days), and week 4 (22-28 days) from the initial onset of symptoms, for analyses of complete blood cell counts and cell counts of lymphocyte subsets $\left(\mathrm{CD} 4^{+} \mathrm{T}\right.$ cell, $\mathrm{CD}^{+} \mathrm{T}$ cell, $B$ cell, and natural killer $(\mathrm{NK})$ cell counts [cells/ $\mu \mathrm{L}]$ and $\mathrm{CD}^{+} \mathrm{T} / \mathrm{CD}^{+} \mathrm{T}$ ratio). Lymphocyte subsets were detected and counted by BD FACSCalibur flow cytometer (BD Biosciences, San Jose, CA, USA), and the subsets were characterized according to phenotypes of the corresponding CD antigens.

For $\mathrm{T}$ cell subset identification and counting, a Four ColorHuman CD3/CD8/CD45/CD4 Flow Kit was employed, according to manufacturer's instructions. Briefly, $50 \mu \mathrm{L}$ of the isolated peripheral blood mononuclear cells was incubated directly with the Four Color reagent consisting of a combination of RPE-Cy5.5 conjugated CD3 (Mouse IgG1), APC conjugated CD8 (Mouse IgG1), RPE conjugated CD45 (Mouse IgG2a), and fluorescein isothiocyanate (FITC)-conjugated CD4 (mouse IgG1) monoclonal antibodies for $15 \mathrm{~min}$ at $4{ }^{\circ} \mathrm{C}$ in absolute counting tubes. Subsequently, $450 \mu \mathrm{L}$ of red blood cell lysing solution (1xBD lysing solution) was added to the tubes before performing the flow cytometric analysis. The samples were then incubated at room temperature for $5 \mathrm{~min}$ prior to detection by BD FACS Calibur flow cytometer. Data were obtained and analyzed automatically by the MultiSET software.

\section{Statistical analyses}

All analyses were performed using SPSS statistical software (version 26.0, IBM, Armonk, NY, USA). Categorical data are expressed in frequency or percentage, and statistical significance was determined by $\chi^{2}$ or Fisher's exact test. Nonparametric variables are expressed as median with interquartile range (IQR). For continuous data, Mann-Whitney $U$ test or Kruskal Wallis test was performed to compare variables between different groups and determine the statistical significance. In all analyses, $P<0.05$ was statistically significant. The dynamic changes of different subsets of lymphocytes at different time periods are represented by boxplots.

\section{Results \\ Demographic and clinical characteristics of patients with COVID-19 and severe influenza $A$}

In our study, we retrospectively reviewed the clinical data of 94 healthy blood donors (healthy controls), 99 patients with COVID-19 and 37 patients with severe influenza A. The group with healthy controls (HC) comprised of 44 males (47.0\%) and 50 females (53.0\%).Among the 99 patients with COVID-19, 56 were men (56.6\%) and 43 were women (43.4\%).All the COVID-19 patients were divided into two groups, according to the abovementioned diagnostic criteria, and there were 80 non-severe cases $(80.8 \%)$ and 19 severe cases (19.2\%; Table 1). The median age of patients with non-severe and severe COVID-19 was 37 (30-49) years and 67 (53-74) years, respectively. The severe patient group had a higher age than the non-severe COVID-19 group. The median durations of hospitalization of patients with non-severe and severe COVID-19 were 4 (2, $7)$ and $5(4.5,10)$ days, respectively.

All the patients with severe COVID-19 $(n=19,100 \%)$ presented with fever, cough, and dyspnea. On the contrary, only a few patients with non-severe COVID-19 had fever $(n=58,73 \%)$ and cough $(n=38,48 \%)$. Notably, none of them had dyspnea.

A total of 31 (31.3\%) patients in both the COVID-19 groups had pre-existing chronic medical conditions, including diabetes (8 [11\%]), hypertension (24 [32.9\%]), COPD (2 [2.8\%]), cardiovascular disease (2 [2.8\%]), renal disease $(1[1.4 \%])$, and autoimmune disorders (5 [6.9\%]). 
Table 1 Demographic and clinical characteristics of different study groups

\begin{tabular}{|c|c|c|c|c|}
\hline Characteristics & $\begin{array}{l}\text { Healthy Donors } \\
n=94\end{array}$ & $\begin{array}{l}\text { Non-severe COVID-19 } \\
n=80\end{array}$ & $\begin{array}{l}\text { Severe COVID-19 } \\
n=19\end{array}$ & $\begin{array}{l}\text { Severe influenza A } \\
n=37\end{array}$ \\
\hline Age groups (years), median (IQR) & $47(36,68)$ & $37(30,49)$ & $67(53,74)$ & $67(54,84)$ \\
\hline \multicolumn{5}{|l|}{ Gender N, (\%) } \\
\hline Male & $44(47.0)$ & $41(51.0)$ & $15(79.0)$ & $28(76.0)$ \\
\hline Female & $50(53.0)$ & $39(49.0)$ & $4(21.0)$ & $9(24.0)$ \\
\hline Admission time, median (IQR) & / & $4(2,7)$ & $5(4.5,10)$ & $3(2,5)$ \\
\hline \multicolumn{5}{|l|}{ Common Symptoms N,(\%) } \\
\hline Fever & / & $58(73.0)$ & $19(100.0)$ & $37(100.0)$ \\
\hline Cough & / & $38(48.0)$ & $19(100.0)$ & $37(100.0)$ \\
\hline Dyspnea & / & 0 & $19(100.0)$ & $28(76.0)$ \\
\hline \multicolumn{5}{|l|}{ Co-existing complications $\mathrm{N},(\%)$} \\
\hline Other & / & $19(24.0)$ & $12(63.0)$ & $33(89.0)$ \\
\hline Hypertension & / & $16(20.0)$ & $8(42.0)$ & $23(62.0)$ \\
\hline Diabetes & / & $4(5.0)$ & $4(21.0)$ & $9(24.0)$ \\
\hline COPD & / & $1(1.0)$ & $1(5.0)$ & $7(19.0)$ \\
\hline Cardiovascular disease & / & 0 & $2(11.0)$ & $13(35.0)$ \\
\hline Renal disease & / & 0 & $1(5.0)$ & $2(5.0)$ \\
\hline Autoimmune disorders & / & $2(3.0)$ & $3(16.0)$ & $0(0)$ \\
\hline \multicolumn{5}{|l|}{ Outcome N,(\%) } \\
\hline Survival & / & $80(100.0)$ & $18(95.0)$ & $33(89.0)$ \\
\hline Deaths & / & 0 & $1(5.0)$ & $4(11.0)$ \\
\hline
\end{tabular}

Abbreviations: COPD Chronic obstructive pulmonary disease, IQR Interquartile range

Specifically, 19 patients (24\%) with non-severe COVID19 and 12 patients (63\%) with severe COVID-19 presented with one or more of the pre-existing chronic medical conditions (Table 1). One patient in the severe COVID-19 group died on day 28 after the onset of the disease.

Similar to the group with severe COVID-19, the median age of patients with severe influenza $\mathrm{A}$ infection was higher (67 years) than that of those of healthy controls (47 years). Notably, the difference in age was found to be statistically significant $(P<0.05)$ between the groups. All patients with severe influenza A infection $(n=37,100 \%)$ presented with fever and cough. However, only 28 patients $(76.0 \%)$ had dyspnea. Out of 37 patients with severe influenza A, 4 (11.0\%) died and 33(89.0\%) survived (Table 1).

\section{Variations in leukocytes and lymphocyte subsets in COVID-19 and severe influenza $A$ in the first week of illness}

Due to the age difference in the cohort of patients with non-severe COVID-19, severe COVID-19, and severe influenza, the healthy controls were divided into 2 groups (group one and group two). The median age of the healthy controls in group one was 37 $(31,41)$, which age-matched with the non-severe
COVID-19 patients $(P=0.546)$. The median age of the healthy controls in group two was $68(55,77)$ and age-matched with severe COVID-19 and severe influenza patients $(P=0.546$ and $P=0.159$, respectively).

The absolute counts of total white blood cells (WBCs) $\left(5.29 \times 10^{9} / \mathrm{L}\right)$ and lymphocytes $\left(1.51 \times 10^{9} / \mathrm{L}\right)$ of nonsevere COVID-19 patients in the first week of illness were significantly lower than those of the healthy donors in group one $\left(6.01 \times 10^{9} / \mathrm{L}, P=0.007\right.$ and $1.85 \times 10^{9} / \mathrm{L}$, $P=0.001$, respectively). However, there were no significant differences in total $\mathrm{T}$ cells $(P=0.105), \mathrm{CD}^{+} \mathrm{T}$ cells $(P=0.203), \mathrm{CD} 8^{+} \mathrm{T}$ cells $(P=0.068)$ and $\mathrm{CD} 4^{+} / \mathrm{CD} 8^{+}$ ratio $(P=0.193)$ between non-severe COVID-19 patients and healthy controls in group one (Table 2).

The absolute counts of total WBCs of patients with severe COVID-19 $\left(4.55 \times 10^{9} / \mathrm{L}, P=0.275\right)$ and severe influenza A $\left(5.99 \times 10^{9} / \mathrm{L}, P=0.989\right)$ showed no significant differences with the WBCs' counts of the healthy control in group two. The absolute counts of lymphocytes in healthy donors in group two $\left(1.74 \times 10^{9} / \mathrm{L}\right)$ were significantly higher than those of patients with severe COVID$19\left(0.81 \times 10^{9} / \mathrm{L}, P=0.001\right)$, severe influenza A $(0.87 \times$ $\left.10^{9} / \mathrm{L}, P<0.0001\right)$. Patients with severe COVID-19 and severe influenza A had a significantly lower number of total $\mathrm{T}$ cells $(P=0.001$ and $P<0.0001$, respectively $)$, CD4 ${ }^{+} \mathrm{T}$ cells $(P=0.001$ and $P<0.0001$, respectively), 
Table 2 Comparison of cell counts of total WBCs, total lymphocytes, and lymphocyte subsets in patients with non-severe COVID-19 with the first week of illness and Healthy Donors in Group one

\begin{tabular}{|c|c|c|c|c|}
\hline Parameters & Healthy Donors Group one & Non-severe COVID-19 & $z$ & $P$ \\
\hline $\begin{array}{l}\text { WBC }\left(* 10^{9} / \mathrm{L}\right) \\
\text { median (IQR) }\end{array}$ & $6.01(4.94,6.65)$ & $5.29(4.21,6.07)$ & 2.677 & 0.007 \\
\hline $\begin{array}{l}\operatorname{LY}\left({ }^{*} 10^{9} / \mathrm{L}\right) \\
\text { median (IQR) }\end{array}$ & $1.85(1.66,2.46)$ & $1.51(1.35,1.97)$ & 3.311 & 0.001 \\
\hline T cell count (cells/mm³), median (IQR) & $1303(1139,1641)$ & $1199(883,1582)$ & 1.622 & 0.105 \\
\hline $\mathrm{CD}^{+}$count $\left(\right.$cells $\left./ \mathrm{mm}^{3}\right)$, median (IQR) & $711(567,815)$ & $680(472,819)$ & 1.272 & 0.203 \\
\hline $\mathrm{CD}^{+}$count $\left(\right.$cells $\left./ \mathrm{mm}^{3}\right)$, median (IQR) & $562(436,733)$ & $421(356,709)$ & 1.826 & 0.068 \\
\hline $\mathrm{CD}^{+} / \mathrm{CD}^{+}$ratio, median (IQR) & $1.22(0.95,1.76)$ & $1.57(1.01,1.97)$ & 1.303 & 0.193 \\
\hline
\end{tabular}

Abbreviations: WBC White blood cells, $L Y$ Lymphocytes, IQR Interquartile range; $P<0.05$ is statistically significant

and $\mathrm{CD}^{+} \mathrm{T}$ cells $(P=0.002$ and $P<0.0001$, respectively) than healthy controls in group two. $\mathrm{CD} 4^{+} / \mathrm{CD}^{+}$ ratio in severe COVID-19 and severe influenza A demonstrated no significant differences compared with those in healthy controls in group two $(P=0.334$ and $P=$ 0.564 , respectively). Further, there were no significant differences in peripheral blood leukocytes, lymphocytes and total $\mathrm{T}$ cells, CD4+ $\mathrm{T}$ cells, CD8 $+\mathrm{T}$ cells and $\mathrm{CD} 4+/ \mathrm{CD} 8+$ ratio in patients with severe COVID-19 and severe influenza $\mathrm{A}$ in the first week after illness onset (Table 3).

\section{Dynamic changes in leukocyte and lymphocyte subset counts with disease progression}

To further determine dynamic changes in the immune cell subsets of patients with non-severe COVID-19, severe COVID-19, and severe influenza $A$, with disease evolution, we compared the absolute counts of leukocytes, total lymphocytes, and lymphocyte subsets of each cohort at weeks $1,2,3$, and 4 respectively.

The leukocyte counts of patients with non-severe COVID-19 were significantly higher in week 3 than those of week 1 and week 2 (W1-W3: $P=0.005$, W2W3: $P=0.044)$. A similar tendency was seen with lymphocyte count, which showed a sharp significant increase at week 3 compared with that seen at week 1 (W1-W3: $P=0.004)$. Interestingly, a significant change in total $\mathrm{T}$ cell count was observed at week 3 , suggesting a marked increase in total $\mathrm{T}$ cell population when compared with that observed at week $2(\mathrm{~W} 2-\mathrm{W} 3: P=0.045)$ (Fig. 1a-c). The total leukocyte, lymphocyte, and $\mathrm{T}$ cell counts demonstrated no significant difference at week 3 in patients with non-severe COVID-19 compared with healthy donors in group one. No significant changes were seen $\mathrm{CD}^{+} \mathrm{T}, \mathrm{CD} 8^{+} \mathrm{T}$ cells and $\mathrm{CD} 4^{+} / \mathrm{CD} 8^{+}$ratios of patients with non-severe COVID-19 during the 4 weeks following the infection (Fig. 1d-f).

In patients with severe COVID-19, White blood cells gradually recovered and the variations in leukocyte counts were found to be statistically significant (W1W2: $P=0.013$, W1-W3: $P=0.003$, W1-W4: $P=0.001$ ). A similar trend was observed with total lymphocyte count, which sharply increased at week 3 , showing a significant difference compared to those at weeks 1 and 2(W1-W3: $P=0.013$, W1-W4: $P=0.002$, W2-W3: $P=$ 0.001) (Fig. 2a, b). In addition, a significant and a drastic increase was noted in the cell counts of total $\mathrm{T}$ cell and $\mathrm{CD} 4^{+} \mathrm{T}$ cell subset at week 4 when compared with those of weeks 1 and 2. (W1-W4: $P=0.034$, W2-W4: $P=$ 0.003; W1-W4: $P=0.020$, W2-W4: $P=0.001)$. Although

Table 3 Summary of comparison of cell counts of total WBCs, total lymphocytes, and lymphocyte subsets in severe COVID-19 and severe influenza A cases in the first week of illness with healthy donors group two

\begin{tabular}{|c|c|c|c|c|c|c|c|c|c|}
\hline \multirow[t]{2}{*}{ Parameters } & $\begin{array}{l}\text { Healthy Donors } \\
\text { Group two }\end{array}$ & Severe COVID-19 & Severe FLU A & Z & $\mathbf{P}$ & Z & $\mathbf{P}$ & Z & $\mathbf{P}$ \\
\hline & $\mathbf{I}$ & II & III & I:II & I:II & I:III & I:III & II:III & II:III \\
\hline $\begin{array}{l}\overline{W B C}\left({ }^{*} 10^{9} / \mathrm{L}\right) \\
\text { median }(\mathrm{IQR})\end{array}$ & $6.05(5.09,6.75)$ & $4.55(2.70,6.93)$ & $5.99(3.99,8.10)$ & 1.091 & 0.275 & 0.014 & 0.989 & 1.054 & 0.292 \\
\hline $\begin{array}{l}\mathrm{LY}\left({ }^{*} 10^{9} / \mathrm{L}\right) \\
\text { median (IQR) }\end{array}$ & $1.74(1.41,2.04)$ & $0.81(0.63,1.03)$ & $0.87(0.56,1.42)$ & 3.219 & 0.001 & 5.616 & 0.000 & 0.154 & 0.878 \\
\hline T cell count (cells $\left./ \mathrm{mm}^{3}\right)$, median (IQR) & $1198(1030,1507)$ & $461(388,477)$ & $474(357,747)$ & 3.29 & 0.001 & 6.848 & 0.000 & 0.505 & 0.613 \\
\hline $\mathrm{CD}^{+}$count $\left(\right.$cells $\left./ \mathrm{mm}^{3}\right)$, median (IQR) & $645(528,891)$ & $288(202,329)$ & $283(169,406)$ & 3.29 & 0.001 & 6.404 & 0.000 & 0.242 & 0.809 \\
\hline $\mathrm{CD}^{+}$count $\left(\right.$cells $\left./ \mathrm{mm}^{3}\right)$, median (IQR) & $460(363,716)$ & $144(72,229)$ & $201(138,305)$ & 3.147 & 0.002 & 5.900 & 0.000 & 1.296 & 0.195 \\
\hline $\mathrm{CD}^{+} / \mathrm{CD}^{+}$ratio, median (IQR) & $1.43(1.00,2.14)$ & $2.15(0.96,5.09)$ & $1.32(0.99,1.89)$ & 0.966 & 0.334 & 0.577 & 0.564 & 1.187 & 0.235 \\
\hline
\end{tabular}

Abbreviations: WBC White blood cells, $L Y$ Lymphocytes, IQR Interquartile range; $P<0.05$ is statistically significant 


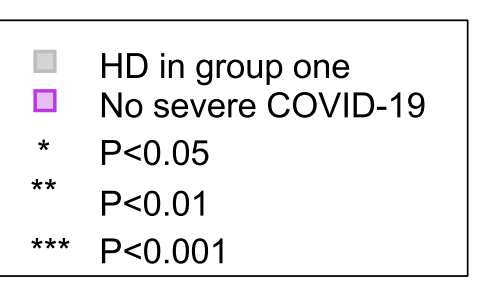

A

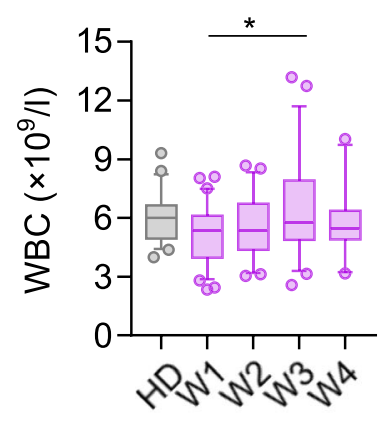

C

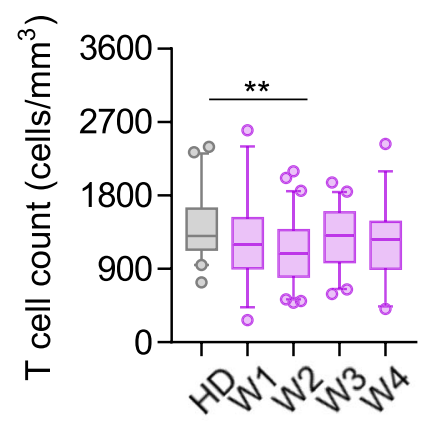

E

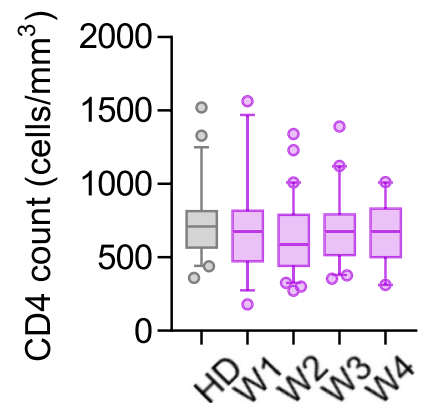

B

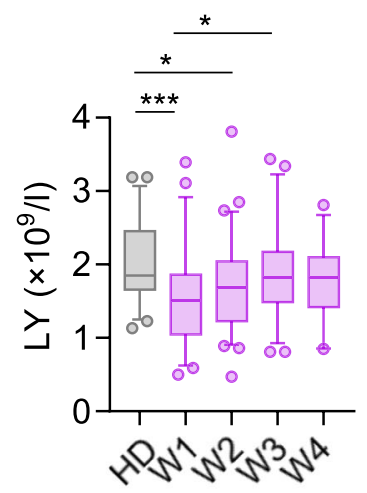

D

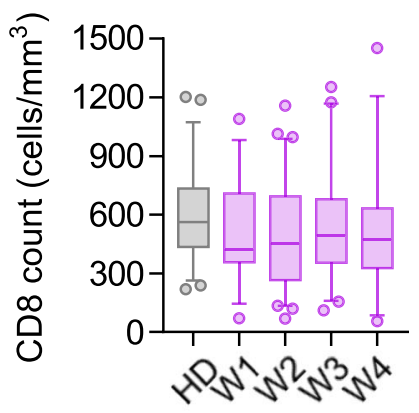

F

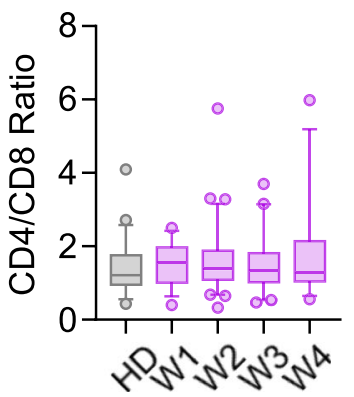

Fig. 1 Dynamic variations in cell counts of total WBCs, total lymphocytes, and lymphocyte subsets in patients with non-severe COVID-19 at weeks (W) 1, 2, 3, and 4 during the course of illness 


\begin{tabular}{|cl|}
\hline$\square$ & HD in group two \\
$\square$ & Severe COVID-19 \\
$\square$ & Severe Flu A \\
$*$ & $P<0.05$ \\
$* *$ & $P<0.01$ \\
$* * *$ & $P<0.001$
\end{tabular}

A

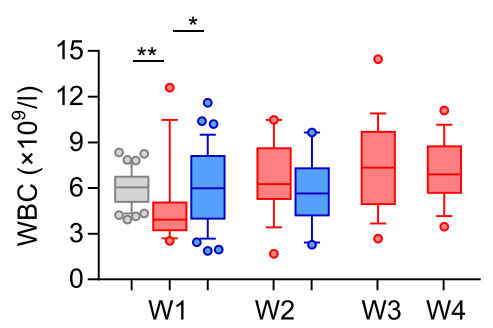

C

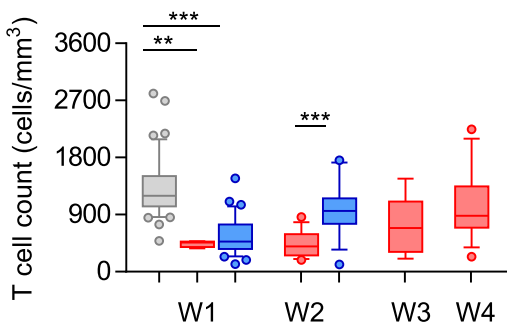

E

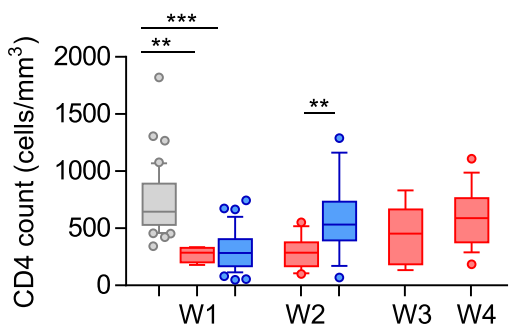

B

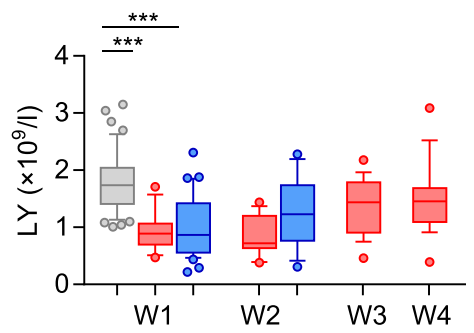

D

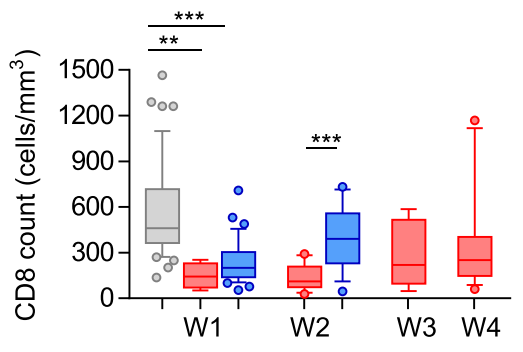

F

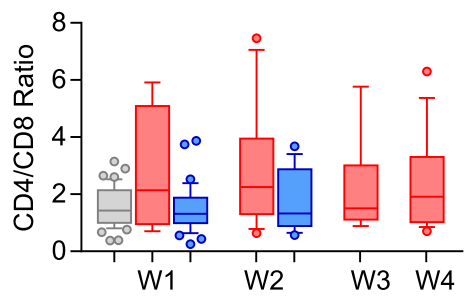

Fig. 2 Dynamic variations in cell counts of total WBCs, total lymphocytes, and lymphocyte subsets in patients with severe COVID-19 and severe influenza A at weeks (W) 1, 2, 3, and 4 during the course of illness. $\mathbf{a}-\mathbf{b}$ Box plots illustrating percentages of total WBCs and total lymphocytes in different groups at different times. Kruskal-Wallis test followed by Dunn's multiple comparisons test or one-way analysis of variance (ANOVA) test followed by Tukey's multiple comparisons test was performed to determine significant differences between the groups. c-f Box plots illustrating total cell counts of T lymphocyte subsets in different groups at different times. Spearman's nonparametric test was used to test for correlations. * $P<0.05$, ${ }^{* *} P<0.01,{ }^{* * *} P<0.001$ were considered significant

$\mathrm{CD} 8^{+} \mathrm{T}$ cells gradually increased from week 1 to week 4 , their counts were still significantly lower than healthy controls in group two at week 4(Fig. 2c-e).

On the contrary, in patients with severe influenza A infection, significant changes were only evident in the cell counts of total $\mathrm{T}$ cells, $\mathrm{CD} 4^{+}$and $\mathrm{CD} 8^{+} \mathrm{T}$ cell subsets (W1-W2: $P=0.001, P=0.002$, and $P=0.007$, respectively) (Fig. 2c-e).
$\mathrm{CD}^{+} / \mathrm{CD}^{+}$ratios of patients with severe COVID-19 and severe influenza A patients showed no significant changes during the 4 weeks after illness onset (Fig. 2f).

\section{Discussion}

In this study, we aimed to analyze the role of lymphocyte subsets in the immunopathogenesis of COVID-19 and severe influenza $\mathrm{A}$, and examined the clinical 
significance of their alterations, especially in determining the prognosis and recovery duration. Our analyses revealed significant dynamic variations in total lymphocytes and lymphocyte subsets, which get activated in the early stages of COVID-19 and severe influenza A infections, and further demonstrated that severe immune injury tended to be more prominent in patients with severe form of the disease. The recovery rate of patients with severe COVID-19 was comparatively longer than those who received immediate antiviral treatment for severe influenza $\mathrm{A}$ and those with non-severe COVID-19.

We retrospectively reviewed the clinical data of $99 \mathrm{pa}$ tients who were confirmed to have COVID-19, 37 patients with severe influenza $\mathrm{A}$ and 94 healthy blood donors who were previously recruited in 2018. All the patients with COVID-19 were divided into two groups, according to the abovementioned diagnostic criteria, including 80 non-severe cases (80.8\%) and 19 severe cases (19.2\%). Several reports and studies have clearly indicated that older or elderly people are more prone to COVID-19 as their immune systems are likely to get overwhelmed by infections due to their advanced age. Similarly, the elderly who are 65 years or older are particularly at risk for influenza infection, hospitalization, and death due to influenza-related complications, such as pneumonia [12]. In our study, the median age of patients with non-severe COVID-19 was 37 years, while that of those with severe COVID-19 was 67 years. Consistent with the previous studies, our data indicate that the ages of the severe patient group are higher than those of the non-severe COVID-19 group. Further, our study showed that the median age of patients with severe influenza $A$ infection was higher (67 years) than that of those with non-severe COVID-19 (37 years) and healthy controls (47 years). Notably, this difference in age was found to be statistically significant $(P<0.05)$ among the groups, which suggests that the elderly people represent a large at-risk population.

The WHO-China joint report on COVID-19 provided a comprehensive symptomatology of COVID-19 $(n=55$, 924) [13]. A previous study showed that patients with COVID-19 present with pyrexia in $85 \%$ of cases during their illness course, but only $45 \%$ are febrile on early presentation. In addition to cough (67.7\%) and sputum (33.4\%), respiratory symptoms, such as dyspnea, sore throat, and nasal congestion were reported to be present in 18.6, 13.9, and $4.8 \%$ of cases, respectively. Both COVID-19 and influenza present with common clinical manifestations including fever, cough, rhinitis, sore throat, headache, dyspnea, and myalgia [7, 14, 15]. In our study, all the patients with severe COVID-19 presented with fever, cough, and dyspnea, whereas only 73 and $48 \%$ of patients with non-severe COVID-19 had fever and cough, respectively. Similar to the severe
COVID-19 group, all patients with severe influenza A infection presented with fever and cough. However, only $76.0 \%$ of the patients had dyspnea. These clinical manifestations of COVID-19 and influenza infections were consistent with other studies. As previously reported the mortality rate also increases in patients with additional comorbidities [3]. Specifically, 63 and $89 \%$ patients with severe COVID-19 and severe influenza A, respectively, presented with one or more pre-existing chronic medical conditions. While the mortality rate was $5 \%$ due to severe COVID-19, it was even higher (11\%) for severe influenza A.

Lymphocytes and their subsets play a crucial role in maintaining immune homeostasis and inflammatory response in the host. As in case of immune disorders and other infections, a viral infection impairs the host's immune defenses and results in decreased levels of lymphocytes and their subsets $[16,17]$. Lymphocyte subsets, namely $\mathrm{CD} 4^{+} \mathrm{T}$ cells, $\mathrm{CD} 8^{+} \mathrm{T}$ cells, B cells, and NK cells are primarily involved in the humoral and cytotoxic immunity against viral infection. Therefore, this necessitates the need to understand the mechanism of reduced blood lymphocyte levels and characterize the dynamic alterations of lymphocyte subsets to provide novel insights for an effective treatment and prognosis of COVID-19.As lymphopenia is frequently observed during the initial stages of respiratory viral infection $[3,18]$. We identified and analyzed different variations in leukocytes, lymphocytes, and $\mathrm{T}$ lymphocyte subsets in patients with non-severe and severe COVID-19 and severe influenza A.. The counts of WBCs and lymphocytes, but not the counts of $\mathrm{T}$ cells, nor $\mathrm{CD} 4^{+}$or $\mathrm{CD}^{+} \mathrm{T}$ cells of nonsevere COVID-19 patients decreased significantly compared with healthy controls in group one during the first week of illness. No significant changes were seen $\mathrm{CD} 4^{+}$ $\mathrm{T}, \mathrm{CD}^{+} \mathrm{T}$ cells and $\mathrm{CD} 4^{+} / \mathrm{CD}^{+}$ratios of patients with non-severe COVID-19 during the 4 weeks following the infection. On the contrary, the counts of $\mathrm{T}$ cells, $\mathrm{CD} 4^{+}$ and $\mathrm{CD}^{+} \mathrm{T}$ cells in patients with severe COVID-19 were significantly lower than those of healthy controls in group two from week1 to week3 after illness onset. Further, $\mathrm{CD} 8^{+} \mathrm{T}$ cells did not improve significantly at week 4 of illness compared with healthy controls. Although the counts of WBCs, lymphocytes and T lymphocyte subpopulations were not compared between non-severe and severe COVID-19 patients due to the age mismatch, this results still suggested that $\mathrm{T}$ lymphocytes and their subsets were damaged more drastically in severe COVID-19 patients. These findings are corroborated by a previous study which hypothesized that the virus might directly infect lymphocytes resulting in their apoptosis, thus leading to causing a sharp decline in total lymphocyte population and subsequent lymphopenia. Moreover, lymphocytes express the coronavirus receptor 
angiotensin-convertingenzyme 2(ACE-2), and therefore are a direct target for the virus [19]. Another retrospective study suggested that lymphopenia might be one of the predictive factors for progression to respiratory failure during early stages following Middle East Respiratory Syndrome coronavirus (MERS-Cov) infection [20]. Giving further strength to our study, a study by Geng et al. demonstrated the decline in the populations of $\mathrm{T}$ lymphocytes and their subsets, after influenza A virus infection, to be positively correlated with prognosis [21]. Meantime, our results reiterate the fact that CD8+ T cell responses play a major role in antiviral immunity [22]. Taken together, lymphopenia was common in the patients with COVID-19, indicating a significant impairment in the host's immune system following SARS$\mathrm{CoV}-2$ and influenza A infections. Our findings are in line with other studies which also detected these alterations in patients with pneumonia caused by MERS-CoV and Severe acute respiratory syndrome coronavirus (SARS-CoV) [20, 23]. In addition, a significant reduction in both $\mathrm{CD} 4^{+} \mathrm{T}$ cells and $\mathrm{CD} 8+\mathrm{T}$ cells were specifically observed in patients with severe COVID-19 and severe influenza A. Therefore, this indicates a more severe immune insult in patients with the severe form of the disease. Consequently, the alteration would be more profound, and leads to adverse clinical outcome in these patients. Thus, lymphocytes and their subsets, especially $\mathrm{CD}^{+} \mathrm{T}$ cells, might be a potential predictor for disease severity and clinical efficacy in COVID-19.

Next, we focused on the dynamics of $\mathrm{T}$ lymphocytes and their subsets, which played a vital role in cellular immune responses. We compared the absolute counts of leukocytes, total lymphocytes, and lymphocyte subsets of the non-severe and severe COVID-19 patient groups at weeks 2,3 , and 4 with that of those observed during the initial stages of infection. The total leukocyte, lymphocyte, and $\mathrm{T}$ cell counts significantly improved at week 3 in patients with non-severe COVID-19. Lymphocyte also recovered markedly at week 3 in severe COVID-19 patients. However, $\mathrm{T}$ cell and $\mathrm{CD} 4^{+} \mathrm{T}$ cell subset population significantly increased at week 4 in patients with severe COVID-19. Our results are consistent with a previous study by $\mathrm{He}$ et al. that showed a sharp decline (below normal) in the cell counts of $\mathrm{CD}_{4} 5^{+}, \mathrm{CD}^{+} \mathrm{T}$ cell subsets, $\mathrm{CD}^{+} \mathrm{T}$ cell subsets, and $\mathrm{CD}^{+} \mathrm{T}$ cell subsets during the first week of SARS-Cov infection; their values further declined during the second week before increasing during the third week and returning to normal by the fifth week. Moreover, $\mathrm{CD} 4^{+} \mathrm{T}$ and $\mathrm{CD}^{+} \mathrm{T}$ cell counts were found to be extremely low in critically ill and deceased patients [23]. Taken together, the alterations in lymphocytes and their subsets gradually improved at later time points in patients with COVID-19. Collectively, our results indicate that the recovery duration of patients with severe COVID-19 is longer than those with the mild form of the disease.

Our study results further revealed a noticeable difference in the time taken for the cell counts to improve among the severe and non-severe COVID-19 and the severe influenza groups. The cell counts of total lymphocytes and their subsets recovered only around week 4 in severe COVID-19; the recovery time was almost delayed by a week compared with those having non-severe COVID-19. On the contrary, the cell counts of total lymphocytes and their subsets in patients with severe influenza A increased and improved drastically at week2; this rapid recovery rate could be attributed to the early initiation of treatment with the neuraminidase inhibitor, oseltamivir, or peramivir, which interfere with virus release from host cells by blocking the viral nucleic acid function, thus preventing infection of new host cells [24].

The relative role(s) played by the immune response to SARS-CoV-2 versus direct viral effects in the respiratory system and other organ systems has been questioned, with the possibility of immunopathogenesis being a major causal component of severe COVID-19 [25, 26]. Limited by research conditions, our study only demonstrated that severe COVID-19 cases had significant lymphopenia, especially the helper $\left(\mathrm{CD}^{+} \mathrm{CD} 4^{+}\right)$and cytotoxic $\mathrm{T}$ cells $\left(\mathrm{CD}^{+} \mathrm{CD}^{+}\right)$, in the early stage of illness onset, consistent with previous research results, and lymphocytes and their subgroups in severe COVID-19 patients require a longer recovery period, compared with severe influenza patients. These results can give more points to other studies about $\mathrm{T}$ lymphocyte dynamic. The percentage of naïve helper $\mathrm{T}$ cells increased and memory helper $\mathrm{T}$ cells decreased in severe cases may be an important phenomenon in lymphopenia of severe COVID-19 patients [27]. Moreover, the function of $\mathrm{CD}^{+}{ }^{+} \mathrm{T}$ cells, $\mathrm{CD}^{+} \mathrm{T}$ cells and NK cells was within normal range which indicated by PMA/Ionomycin stimulated IFN- $\gamma$ positive cells in these three subsets, and there was no significant difference between severe and non-severe COVID-19 cases. At the same time, T cell counts recovered was related to the concentration of cytokines in plasma likes IL-6, IL-10, and TNF- $\alpha$, which was decreased in the disease resolution stage of COVID19 patients [28]. They also observed that increasing exhausted marker PD-1 expression on T cells was tested as COVID-19 patients progressed from prodromal to overtly symptomatic stages, which demonstrated that the surviving $\mathrm{T}$ cells appear functionally exhausted, not just a decrease in $\mathrm{T}$ cell counts. In summary, we would continue further studies on the function of $\mathrm{T}$ cell subsets across the spectrum of COVID-19 disease severity to gain insights into SARS-CoV-2 potential immunopathogenesis. 
Our study has several limitations. Firstly, this study was retrospective, small single-center, cross-sectional clinical study. Only a small sample of 99 patients with COVID-19 admitted to Beijing Ditan Hospital was included, which may confound the results and potentially introduce selection bias. This may limit the generalizability of the study. At the same time, the study cohort was limited by the actual conditions of the admitted patients. Among the 99 COVID-19 patients, there were 80 non-severe cases and 19 severe ones. Nonsevere COVID-19 patients were mainly young people, while severe COVID-19 patients were mainly elderly patients. The age data of the non-severe and severe COVID-19 cohorts could not be matched. In addition, inconsistencies in time periods between illness onset and admission might have led to missing data which could result in observation biases in the dynamic variations in immune cells.

\section{Conclusions}

Collectively, our study suggests the plausible role of lymphocyte subsets in disease progression, which in turn affects prognosis and recovery duration in patients with severe COVID-19 and influenza A. The dynamic alterations in lymphocytes and their subsets provides valuable insights into the immunopathogenesis of disease progression in COVID-19.

\section{Supplementary Information}

The online version contains supplementary material available at https://doi. org/10.1186/s12879-020-05637-9.

Additional file 1 : Supplementary Table 1. Dynamic variations in cell counts of total WBCs, total lymphocytes, and lymphocyte subsets in patients with non-severe COVID-19, severe COVID-19, and severe influenza $A$ at weeks 1, 2, 3, and 4. Values represent $P$ values.

\section{Abbreviations}

COVID-19: Coronavirus disease-19; WHO: World Health Organization; SARSCoV-2: Severe acute respiratory syndrome coronavirus 2; CT: Computed tomography; RT-PCR: Reverse transcription-polymerase chain reaction; RNA: Ribonucleic acid; HIV: Human immunodeficiency virus; COPD: Chronic obstructive pulmonary disease; CDC: Center for Disease Control and Prevention; NK: Natural killer; IQR: Interquartile range; HC: Healthy controls; WBC: White blood cells; LY: Lymphocytes; ACE-2: Angiotensinconvertingenzyme 2; MERS- CoV: Middle East Respiratory Syndrome coronavirus; SARS-CoV: Severe acute respiratory syndrome coronavirus

\section{Acknowledgments}

We acknowledge all health-care workers involved in the diagnosis and treatment of patients in Beijing Ditan Hospital, Capital Medical University.

\section{Authors' contributions}

FZ and ZC were responsible for the study concept and design. They had complete access to all the data in this study and take responsibility for data integrity and accuracy of the data analysis. FQ and YS contributed to the writing of this manuscript. FQ, GG, YX, AW, SW, XM, TZ and XG contributed to the sample acquisition of patients, diagnosis, and treatment. FQ and YS contributed to data collection, data interpretation, and analysis of the results. $\mathrm{YH}$ and $\mathrm{MC}$ conducted the statistical analyses. All authors reviewed and approved the final manuscript.
Funding

None.

Availability of data and materials

The datasets used and/or analysed during the current study are available from the corresponding author on reasonable request.

\section{Ethics approval and consent to participate}

This study was approved by the Ethics Committee of Beijing Ditan Hospital (No. 202000601). The need for individual consent was waived because of the retrospective nature of the study.

Consent for publication

Not applicable.

\section{Competing interests}

The authors declare that they have no competing interests.

\section{Author details}

${ }^{1}$ Clinical and Research Center of Infectious Diseases, Beijing Ditan Hospital, Capital Medical University, No.8, Jing shun Dong jie, Chaoyang 100015, District Beijing, China. ${ }^{2}$ Department of Medical Records and Statistics, Beijing Ditan Hospital, Capital Medical University, Beijing, China. ${ }^{3}$ Department of Neurology, Beijing Ditan Hospital, Capital Medical University, Beijing, China. ${ }^{4}$ Department of Oncology, Beijing Ditan Hospital, Capital Medical University, Beijing, China.

Received: 24 July 2020 Accepted: 19 November 2020

Published online: 01 December 2020

\section{References}

1. Fauci AS, Lane HC, Redfield RR. Covid-19 - navigating the uncharted. N Engl J Med. 2020;382(13):1268-9.

2. United States Centers for Disease Control and Prevention. Interim quidance on the use of influenza antiviral agents during the 2010-2011 influenza season. http://www.cdc.ov/flu/professionals/antivirals/guidance/summary. html. Accessed 20 Mar 2020.

3. Kakodkar P, Kaka N, Baig MN. A comprehensive literature review on the clinical presentation, and management of the pandemic Coronavirus Disease 2019 (COVID-19). Cureus. 2020;12(4):e7560.

4. Guo X, Chen Y, Li X, Kong H, Yang S, Ye B, et al. Dynamic variations in the peripheral blood lymphocyte subgroups of patients with 2009 pandemic H1N1 swine-origin influenza A virus infection. Virol J. 2011;8:215.

5. Nichols JE, Niles JA, Roberts NJ Jr. Human lymphocyte apoptosis after exposure to influenza A virus. J Virol. 2001;75(13):5921-9.

6. Chen N, Zhou M, Dong X, Qu J, Gong F, Han Y, et al. Epidemiological and clinical characteristics of 99 cases of 2019 novel coronavirus pneumonia in Wuhan, China: a descriptive study. Lancet. 2020;395(10223):507-13.

7. Guan WJ, Ni ZY, Hu Y, Liang WH, Ou CQ, He JX, et al. Clinical characteristics of coronavirus disease 2019 in China. N Engl J Med. 2020;382(18):1708-20.

8. Tan L, Wang Q, Zhang D, Ding J, Huang Q, Tang YQ, et al. Lymphopenia predicts disease severity of COVID-19: a descriptive and predictive study. Signal Transduct Target Ther. 2020;5(1):33.

9. National Health Commission of the People's Republic of China. Diagnosis and Treatment Protocols for Patients with COVID-19 (Trial Version7, Revised). http://www.nhc.gov.cn/yzygj/s7652m/202003/a31191442e29474b98bfed55 79d5a f95.shtml. Accessed 16 Jul 2020.

10. National Health Commission of the People's Republic of China. Diagnosis and Treatment Protocols for Patients with influenza (Version2019). http:// www.nhc.gov.cn/yzygj/s7653p/201911/a577415af4e5449cb30ecc6511e36 9c7.shtml. Accessed 16 Jul 2020.

11. World Health Orgazation. Clinical management of severe acute respiratory infection when novel coronavirus ( $\mathrm{nCoV}$ ) infection is suspected: interim guidance. Accessed at https://www.who.int/publications-detail/clinicalmanagement-of-severe-acute-respiraory-infection-whennovel-coronavirus(ncov)-infection-is-suspected. Accessed 16 Jul 2020.

12. Wilhelm M. Influenza in older patients: a call to action and recent updates for vaccinations. Am J Manag Care. 2018;24(2 Suppl):S15-24.

13. World Health Organization. WHO-China joint mission on coronavirus disease 2019(COVID-19). Accessed at https://www.who.int/news-room/feature- 
stories/detail/who-china-joint-mission-on-coronavirus-disease-2019. Accessed 28 Mar 2020.

14. Ozaras R, Cirpin R, Duran A, Duman H, Arslan O, Bakcan Y, et al. Influenza and COVID-19 coinfection: report of six cases and review of the literature. J Med Virol. 2020. https://doi.org/10.1002/jmv.26125.

15. Shi H, Han X, Jiang N, Cao Y, Alwalid O, Gu J, et al. Radiological findings from 81 patients with COVID-19 pneumonia in Wuhan, China: a descriptive study. Lancet Infect Dis. 2020;20(4):425-34.

16. Chan MH, Wong WW, Wong CK, Chan PK, Chu CM, Hui DS, et al. Serum LD1 isoenzyme and blood lymphocyte subsets as prognostic indicators for severe acute respiratory syndrome. J Intern Med. 2004;255(4):512-8.

17. Su R, Li Z, Wang Y, Liu Y, Zheng X, Gao C, et al. Imbalance between Th17 and regulatory $T$ cells in patients with systemic lupus erythematosus combined EBV/CMV viraemia. Clin Exp Rheumatol. 2019;38(5):864-73.

18. Cheng Y, Zhao H, Song P, Zhang Z, Chen J, Zhou YH. Dynamic changes of lymphocyte counts in adult patients with severe pandemic H1N1 influenza A. J Infect Public Health. 2019;12(6):878-83.

19. Xu H, Zhong L, Deng J, Peng J, Dan H, Zeng X, et al. High expression of ACE2 receptor of 2019-nCoV on the epithelial cells of oral mucosa. Int J Oral Sci. 2020;12(1):8.

20. Ko JH, Park GE, Lee JY, Lee JY, Cho SY, Ha YE, et al. Predictive factors for pneumonia development and progression to respiratory failure in MERS CoV infected patients. J Inf Secur. 2016;73(5):468-75.

21. Lin $L$, Lu L, Cao W, Li T. Hypothesis for potential pathogenesis of SARS-CoV2 infection-a review of immune changes in patients with viral pneumonia. Emerg Microbes Infect. 2020:9(1):727-32.

22. Sant AJ, McMichael A. Revealing the role of CD4(+) T cells in viral immunity. J Exp Med. 2012;209(8):1391-5

23. He Z, Zhao C, Dong Q, Zhuang H, Song S, Peng G, et al. Effects of severe acute respiratory syndrome (SARS) coronavirus infection on peripheral blood lymphocytes and their subsets. Int J Infect Dis. 2005;9(6):323-30

24. Doucette KE, Aoki FY. Oseltamivir: a clinical and pharmacological perspective. Expert Opin Pharmacother. 2001;2(10):1671-83

25. Wilk AJ, Rustagi A, Zhao NQ, Roque J, Martinez-Colon GJ, McKechnie JL, et al. A single-cell atlas of the peripheral immune response in patients with severe COVID-19. Nat Med. 2020;26(7):1070-6.

26. Vabret N, Britton GJ, Gruber C, et al. Immunology of COVID-19: current state of the science. Immunity. 2020;52(6):910-41.

27. Qin C, Zhou L, Hu Z, et al. Dysregulation of immune response in patients with COVID-19 in Wuhan, China. Clin Infect Dis. 2020;71(15):762-8.

28. Diao B, Wang C, Tan Y, et al. Reduction and functional exhaustion of T cells in patients with coronavirus disease 2019 (COVID-19). Front Immunol. 2020; 11:827.

\section{Publisher's Note}

Springer Nature remains neutral with regard to jurisdictional claims in published maps and institutional affiliations.

Ready to submit your research? Choose BMC and benefit from:

- fast, convenient online submission

- thorough peer review by experienced researchers in your field

- rapid publication on acceptance

- support for research data, including large and complex data types

- gold Open Access which fosters wider collaboration and increased citations

- maximum visibility for your research: over $100 \mathrm{M}$ website views per year

At $\mathrm{BMC}$, research is always in progress.

Learn more biomedcentral.com/submissions 